\title{
The 16th Annual Meeting of the Japanese Gastroenterological Association
}

The 16th Annual Meeting of the Japanese Gastroenterological Association (JGA) was organized by Prof. Yoshikazu Kinoshita, Department of Gastroenterology, Shimane University, and was held in Himeji on February 7 to 8,2020 . During this conference, special lectures, educational lectures, core symposia, workshops, and one international session (IGICS) were held among general presentations.

Articles published in the present Digestion JGA Special Issue 2021 represent the best presentations from the 16th Annual Meeting. The session chairpersons and editorial board members recommended numerous papers from their sections; subsequently, the editorial committee of the JGA selected distinguished presentations from these recommendations and invited the authors to submit their papers for this special issue. All manuscripts were inde- pendently reviewed by 2 members of the JGA editorial committee.

We believe this issue will provide useful information to clinicians and investigators. We wish to express our sincere gratitude to all the authors, chairpersons, and editorial board members for their contributions to this special issue.

\section{Conflict of Interest Statement}

Akira Andoh is the acting editor for the publication of this special issue sponsored by the JGA. He is a member of the Board of Directors of the JGA and serves as the JGA Editorial Representative for Digestion, the official journal of the JGA.

Akira Andoh, $M D, P h D$ Editorial chief of the JGA Editorial Committee. 